\title{
Morphological Abnormalities of Thalamic Subnuclei in Migraine: A Multicenter MRI Study at 3 Tesla
}

\author{
Stefano Magon, ${ }^{1,2}$ Arne May, ${ }^{3}$ Anne Stankewitz, ${ }^{3,4}$ Peter J. Goadsby, ${ }^{5,6}$ Amy R. Tso, ${ }^{5}$ Messoud Ashina, ${ }^{7}$ \\ Faisal Mohammad Amin, ${ }^{7}$ Christian L. Seifert, ${ }^{4}$ M. Mallar Chakravarty, ${ }^{8,9}$ Jannis Müller, ${ }^{1}$ and ${ }^{\circledR}$ Till Sprenger ${ }^{1,10}$ \\ ${ }^{1}$ Department of Neurology and ${ }^{2}$ Medical Image Analysis Center, University Hospital Basel, 4031 Basel, Switzerland, ${ }^{3}$ Department of Systems Neuroscience, \\ University Medical Center Hamburg-Eppendorf, 20246 Hamburg, Germany, ${ }^{4}$ Department of Neurology, Klinikum rechts der Isar, Technische Universitaet \\ Muenchen, 81675 Muenchen, Germany, ${ }^{5}$ Department of Neurology, University of California-San Francisco, San Francisco, California 94143, ${ }^{6}$ NIHR- \\ Wellcome Trust Clinical Research Facility, King's College London, London WC2R 2LS, United Kingdom, ${ }^{7}$ Danish Headache Center and Department of \\ Neurology, Glostrup Hospital, University of Copenhagen, 1165 Copenhagen, Denmark, ${ }^{8}$ Cerebral Imaging Centre, Douglas Mental Health University \\ Institute, Verdun, Quebec H4H 1R3, Canada, ${ }^{9}$ Department of Psychiatry, McGill University, Montreal, Quebec H3A 0G4, Canada, and ${ }^{10}$ Department of \\ Neurology, DKD Helios Klinik Wiesbaden, 65191 Wiesbaden, Germany
}

The thalamus contains third-order relay neurons of the trigeminal system, and animal models as well as preliminary imaging studies in small cohorts of migraine patients have suggested a role of the thalamus in headache pathophysiology. However, larger studies using advanced imaging techniques in substantial patient populations are lacking. In the present study, we investigated changes of thalamic volume and shape in a large multicenter cohort of patients with migraine. High-resolution T1-weighted MRI data acquired at 3 tesla in 131 patients with migraine ( 38 with aura; $30.8 \pm 9$ years old; 109 women; monthly attack frequency: $3.2 \pm 2.5$; disease duration: $14 \pm 8.4$ years) and 115 matched healthy subjects ( $29 \pm 7$ years old; 81 women) from four international tertiary headache centers were analyzed. The thalamus and thalamic subnuclei, striatum, and globus pallidus were segmented using a fully automated multiatlas approach. Deformation-based shape analysis was performed to localize surface abnormalities. Differences between patients with migraine and healthy subjects were assessed using an ANCOVA model. After correction for multiple comparisons, performed using the false discovery rate approach ( $p<0.05$ corrected), significant volume reductions of the following thalamic nuclei were observed in migraineurs: central nuclear complex $\left(F_{(1,233)}=6.79\right)$, anterior nucleus $\left(F_{(1,237)}=7.38\right)$, and lateral dorsal nucleus $\left(F_{(1,238)}=6.79\right)$. Moreover, reduced striatal volume $\left(F_{(1,238)}=6.9\right)$ was observed in patients. This large-scale study indicates structural thalamic abnormalities in patients with migraine. The thalamic nuclei with abnormal volumes are densely connected to the limbic system. The data hence lend support to the view that higher-order integration systems are altered in migraine.

Key words: brain volumes; deep gray matter; migraine; MRI; thalamic nuclei; thalamus

\section{Significance Statement}

This multicenter imaging study shows morphological thalamic abnormalities in a large cohort of patients with episodic migraine compared with healthy subjects using state-of-the-art MRI and advanced, fully automated multiatlas segmentation techniques. The results stress that migraine is a disorder of the CNS in which not only is brain function abnormal, but also brain structure is undergoing significant remodeling.

\section{Introduction}

Migraine is a common, complex, and disabling neurological disorder characterized by repeated attacks with a multitude of sen-

Received June 2, 2015; revised Aug. 29, 2015; accepted Sept. 2, 2015.

Author contributions: S.M., P.J.G., and T.S. designed research;S.M., A.M., A.S., P.J.G., A.R.T., M.A., F.M.A., C.L.S., M.M.C., J.M., and T.S. performed research; S.M. analyzed data; S.M. and T.S. wrote the paper.

S.M. received travel support from Biogen and Genzyme. M.A. received personal compensation from Autonomic Technologies for consulting services. P.J.G. is a consultant for Allergan, Colucid, MAP, MSD, eNeura, ATI, Boston Sci, Lilly, Medtronic, BMS, Amgen, Arteaus, AlderBio, Pfizer Zogenix, Nevrocorp, Ipmax, DrReddy, and Zosano; in the last year, he received research support from Amgen, MSD, eNeura, MAP, and Allergan. M.A. is a consultant or scientific sory symptoms, including head pain (Murray et al., 2012). Approximately $20 \%-30 \%$ of patients with migraine also suffer from aura, manifesting as positive and negative neurological symptoms, most commonly visual disturbance. Despite some advances, especially regarding mechanisms involved in the genera- 
Table 1. Demographic characteristics of study population ${ }^{a}$

\begin{tabular}{|c|c|c|c|c|c|c|}
\hline & \multicolumn{3}{|c|}{ Healthy control subjects } & \multicolumn{3}{|c|}{ Episodic migraine patients } \\
\hline & $N$ & Age (yr) [mean \pm SD (range) $]$ & Gender [female/male (\%)] & $N$ & Age (yr) [mean \pm SD (range)] & Gender [female/male (\%)] \\
\hline Center A & 20 & $30.3 \pm 6.9(25-51)$ & $16(80) / 4(20)$ & 19 & $31 \pm 7.5(23-47)$ & $14(70) / 5(30)$ \\
\hline Center C & 20 & $24.6 \pm 5.8(19-46)$ & $20(100) / 0(0)$ & 21 & $25.2 \pm 6.4(19-47)$ & $21(100) / 0(0)$ \\
\hline Center D, scanner 1 & 7 & $28 \pm 7.3(19-40)$ & $6(86) / 1(14)$ & 23 & $31.3 \pm 8.1(19-47)$ & $18(78) / 5(22)$ \\
\hline Center D, scanner 2 & 15 & $32.6 \pm 8.5(21-52)$ & $12(80) / 3(20)$ & 14 & $33.6 \pm 9.5(23-48)$ & $11(78) / 3(22)$ \\
\hline Whole sample & 115 & $29.1 \pm 7.2(19-52)$ & $81(70) / 34(30)$ & 131 & $30.8 \pm 9(19-53)$ & $109(83) / 22(17)$ \\
\hline
\end{tabular}

${ }^{a}$ Center A, Munich; Center B, Hamburg; Center C, Glostrup; Center D, San Francisco.

Table 2. Clinical characteristics of patients with migraine by center ${ }^{a}$

\begin{tabular}{|c|c|c|c|c|}
\hline & $\begin{array}{l}\text { Duration of migraine disorder } \\
(\mathrm{yr})[\text { mean } \pm S D(\text { range })]\end{array}$ & $\begin{array}{l}\text { Headache days per month } \\
{[\text { mean } \pm S D(\text { range) }]}\end{array}$ & MwA/MwoA (\%) & $\begin{array}{l}\text { Headache side (left/right/bilaterally/ } \\
\text { unspecified) [no. (\%)] }\end{array}$ \\
\hline Center A & $16.9 \pm 6.5(3-26)$ & $2.6 \pm 1.9(0.75-8)$ & $12(63) / 7(37)$ & $6(31) / 4(21) / 9(48) / 0(0)$ \\
\hline Center B & $11.3 \pm 7.1(2-30)$ & $3.5 \pm 2.7(1-15)$ & $21(39) / 33(61)$ & $10(18) / 9(17) / 29(54) / 6(11)$ \\
\hline Center D, scanner 1 & $17.7 \pm 10.6(1-41)$ & $4.1 \pm 2.8(1-9)$ & $4(17) / 19(83)$ & $4(17) / 4(17) / 8(35) / 7(30)$ \\
\hline Center D, scanner 2 & $21.2 \pm 8.4(9-33)$ & $4.2 \pm 2.3(2-10)$ & $0(0) / 14(100)$ & $1(7) / 5(36) / 8(57) / 0(0)$ \\
\hline Whole sample & $14.1 \pm 8.5(1-41)$ & $3.3 \pm 2.5(0.75-15)$ & $38(29) / 93(71)$ & $23(17) / 27(21) / 68(52) / 13(10)$ \\
\hline
\end{tabular}

${ }^{a}$ Center A, Munich; Center B, Hamburg; Center C, Glostrup; Center D, San Francisco.

tion of migraine aura, the pathophysiology of migraine is still poorly understood. Third-order trigeminovascular nociceptive neurons are located in the thalamus and are likely to mediate migraine pain. Indeed, thalamic activation (and activation of other brain areas) has been demonstrated during the headache phase of migraine attacks using $\mathrm{H}_{2}{ }^{15} \mathrm{O}$-PET (Afridi et al., 2005) and most recently even in the premonitory phase of attacks (Maniyar et al., 2014).

Moreover, previous studies using different MRI measures, such as quantitative $\mathrm{T} 1$ and $\mathrm{T} 2{ }^{*}$, magnetization transfer ratio, and fractional anisotropy, have suggested microstructural alterations in the thalamus of patients with migraine with aura (MwA) (Granziera et al., 2014), without aura (MwoA) (Coppola et al., 2014), or in both subgroups (DaSilva et al., 2007). However, other structural MRI studies did not detect significant differences between patients with migraine and healthy subjects in terms of global thalamic volume or local thalamic gray matter density (Rocca et al., 2006; Kim et al., 2008; Valfrè et al., 2008; Granziera et al., 2014).

Although thalamic abnormalities are hence likely to play a role at least in subgroups of patients with migraine, the relatively small sample size of previous studies (ranging from 16 to 27 patients) and partly inconsistent results limit the generalizability of such findings. Moreover, previous studies did not address structural abnormalities of volume and shape in distinct thalamic subregions (subnuclei) in patients with migraine.

The main objective of the present study was to investigate the morphology of the thalamus in a large cohort of patients with migraine and to compare them with healthy subjects using advanced structural neuroimaging techniques. Moreover, the volume and shape of the striatum and globus pallidus were studied as secondary outcomes as abnormalities of those brain areas have also been suggested to contribute to migraine pathophysiology (Maleki et al., 2011).

Correspondence should be addressed to Prof. Dr. Till Sprenger, Department of Neurology, DKD Helios Klinik Wiesbaden, Aukammallee 33, 65191 Wiesbaden, Germany. E-mail: till.sprenger@helios-kliniken.de.

DOI:10.1523/JNEUROSCI.2154-15.2015

Copyright $\odot 2015$ the authors $\quad 0270-6474 / 15 / 3513801-07 \$ 15.00 / 0$

\section{Materials and Methods}

\section{Subjects}

Existing data from four academic headache centers were pooled for this study. The participating centers were located in Germany (Munich and Hamburg), Denmark (Glostrup), and the United States (San Francisco). The structural MRI data provided by the centers had originally been acquired in the context of local functional imaging studies to exclude structural abnormalities and for coregistration purposes. Only data from studies, which had recruited both migraineurs and healthy subjects within the same study context, were considered. Data of patients and controls had to be obtained at the same scanner using the same parameters. None of the structural MRI datasets had previously been analyzed and published using quantitative neuroimaging techniques. Written informed consent was obtained from the participants at each center when the data were acquired. The original study protocols were approved by the local ethics committees and conducted in accordance with the Declaration of Helsinki.

Overall, 246 subjects ( 131 patients with migraine, 38 with aura and 93 without aura, and 115 healthy subjects) with an age range of $18-55$ years were included in the study. All patients met the criteria for episodic migraine as defined by the International Classification of Headache Disorders, second edition (Headache Classification Committee of the International Headache Society, 2013). None of the patients had medication overuse headache. Patients with a previous history of cardiovascular, psychiatric, or neurological disease other than migraine were excluded. Infrequent episodic tension-type headache was allowed in both groups. Table 1 summarizes the demographic characteristics of the patients and healthy subjects. Table 2 summarizes the clinical characteristics of patients. Three patients (two with and one without aura) were on preventive medication (two on $\beta$-blockers, one on an antidepressant). The other patients were not on daily medication.

\section{MRI acquisition}

All MRI datasets were acquired on 3 tesla systems. Patients were interictal at the time of image acquisition. The four centers used different MRI systems and vendors (Siemens, General Electric, and Philips). Table 3 summarizes the relevant parameters used at each site.

\section{MRI analysis}

Subcortical structures (including thalamic subnuclei) were automatically identified using a segmentation method based on a multiatlas strategy. This approach uses the population variability of the cohort being analyzed to refine the final segmentation by using "multiple automatically generated templates from different brains" (MAGeT Brain algo- 
Table 3. MRI parameters used for the acquisition of the high-resolution T1-weighted datasets ${ }^{a}$

\begin{tabular}{|c|c|c|c|c|c|c|c|c|}
\hline & MRI system & Magnetic field (tesla) & Slices & $\mathrm{TE}$ (ms) & TR (ms) & Spatial resolution & Flip angle & Coil channels \\
\hline Center A & Philips Achieva & 3 & 170 & 3.99 & 9000 & Isotropic $1 \mathrm{~mm}$ & 8 & 8 \\
\hline Center B & Siemens TrioTim & 3 & 170 & 2.98 & 2300 & Isotropic $1 \mathrm{~mm}$ & 9 & 12 \\
\hline Center C & Philips Achieva & 3 & 170 & 4.6 & 9900 & Isotropic $1 \mathrm{~mm}$ & 8 & 8 \\
\hline Center D-scanner 1 & GE Signa & 3 & 156 & 1.5 & 6300 & Isotropic $1 \mathrm{~mm}$ & 15 & 8 \\
\hline Center D-scanner 2 & Siemens TrioTim & 3 & 170 & 2.98 & 2300 & Isotropic $1 \mathrm{~mm}$ & 9 & 12 \\
\hline
\end{tabular}

${ }^{a}$ Center A, Munich; Center B, Hamburg; Center C, Glostrup; Center D, San Francisco.

rithm) (Chakravarty et al., 2013). Unlike other multiatlas approaches, the MAGeT algorithm uses a single atlas derived from manually segmented serial histological data as the initial input (Chakravarty et al., 2006). This initial input was used to segment a subset of subjects that are representative for the demographical and/or clinical features of the whole cohort to adequately capture the neuroanatomical variability of the sample (Chakravarty et al., 2008). Thereby, a nonlinear registration (SyN algorithm) (Avants et al., 2008) of the atlas to the data of the chosen subset of subjects is applied. This newly segmented set of subjects was then used as a template library for the remainder of the dataset. Once each subject is matched to each of these templates using this technique, there are numerous candidate segmentations available for each subject that are fused using a voxelwise majority vote (i.e., for each voxel the label occurring most frequently is retained for the final segmentation) (Collins and Pruessner, 2010). Two sets of segmentation were produced using this analysis pipeline: the first included the thalamus, the striatum, and the globus pallidus, and the second one included the thalamic subnuclei using the Hirai and Jones nomenclature (Hirai and Jones, 1989). All segmentations were visually inspected to confirm anatomical accuracy by a trained researcher. Thereby, specific attention was paid to the borders of the thalamus toward cerebrospinal fluid spaces and toward the surrounding white matter. The representative sample, which was chosen from the whole group (matched for age, gender, and migraine subtype to the whole group) to generate the template library included 31 subjects (15 patients with migraine, mean age $34.8 \pm 10.7$ years; 11 MwoA; mean disease duration: $14.2 \pm 10.4$ years; 11 women) and 16 healthy subjects (mean age $32.6 \pm 9.3$ years; 11 women). This number of subjects was found optimal to capture the population variability in previous work, and increasing the number did not increase the accuracy of the method (Pipitone et al., 2014). The ability of the MAGeT brain algorithm to accurately identify thalamic subregions has been previously validated against manual segmentations (Chakravarty et al., 2009b), intraoperative recordings (Chakravarty et al., 2008), and fMRI findings (Chakravarty et al., 2009a). This segmentation approach has previously been used to investigate the morphology of thalamic nuclei in attention deficit hyperactivity disorder (Ivanov et al., 2010), Tourette syndrome (Miller et al., 2010), and multiple sclerosis (Magon et al., 2014).

Shape analysis was performed using an extension of the surface-based methodology proposed by Lerch et al. (2008). First, surface-based representations were generated for each structure. For each subject, 31 nonlinear transformations mapped to the original template were concatenated and then averaged to limit noise and error and to increase accuracy (Frey et al., 2011). The dot products between the nonlinear transformation and the surface model normal were used as indices of shape. Such shape indices were estimated to provide a local measure of inward and outward displacement of the thalamic surface relative to the atlas. Outward displacements indicate that the segmented area/nucleus is smaller than the corresponding point in the template. Local inward displacements indicate that the according area is larger than the template.

Moreover, the native brain volume (nBV) was computed for each subject using the high-resolution T1w images with the fully automated tool "Structural Image Evaluation, using Normalization, of Atrophy" for cross-sectional studies (SIENAX version 2.6) (Smith et al., 2004).

\section{Statistical analysis}

Power analysis. Power analysis was performed for the ANCOVA model by using the $\mathrm{G}^{*}$ Power3 software (Faul et al., 2007) to estimate the detectable effect size for the enrolled sample $(\alpha=0.05$ and power $=0.95)$.
Analysis of volumes. For each segmented structure, patients and healthy subjects were compared using an ANCOVA model, including age, gender, MRI scanner, and $\mathrm{nBV}$ as covariates. The covariates and the interaction terms were added stepwise and kept in the model if statistically significant. For the comparison of patients with MwA and MwoA to healthy controls and for comparisons between the different migraine subtypes, subgroups matched for age, gender, and MRI scanner were selected pseudorandomly: MwA subgroup (mean age: $32.5 \pm 8.7$ years, range: $21-50$ years; 31 women; mean disease duration: $13.3 \pm 8.14$ years; mean days with headache per month: $3.2 \pm$ 1.9), MwoA subgroup (mean age: $32.5 \pm 10.1$ years, range $19-53$ years; 31 women; mean disease duration: $15.8 \pm 9.8$ years, mean days with headache per month: $3.5 \pm 2.8$ ), and healthy subject subgroup (mean age $31.7 \pm 8.7$ years, range: $22-48$ years; 31 women). In patients with predominantly lateralized headache, the volumes of the segmented structures of the hemisphere contralateral to the pain were compared with the ipsilateral hemisphere within these patients. In addition, patients with low headache frequency $(<3$ headache days per month) were compared with patients with higher attack frequency (from 8 to $14 \mathrm{~d}$ per month). For each ANCOVA model, the following assumptions were tested: normality was tested using the Shapiro-Wilk test (Royston, 1982), linearity and homoscedasticity using the Levene's test (Brown and Forsythe, 1974), and homogeneity of the regression slopes was verified using the significance of the interaction terms. Model outliers (standardized residuals $>|3|$ ) were excluded.

Furthermore, hierarchical multiple linear regression (MLR) analysis with two blocks was performed to investigate the relation between volumes and clinical factors in patients. Age, gender, MRI scanner, and $\mathrm{nBV}$ were entered in the model by using a stepwise approach. Then, disease duration and headache days per month were added in the model. For each MLR model, the following assumptions were tested: linearity and homoscedasticity were tested by plotting the regression standardized predicted value. The assumption of normality of the residuals was tested using the Shapiro-Wilk test and the probability-probability plot. Moreover, autocorrelations were tested by using Durbin-Watson test. Colinearity was tested using the variance inflated factor as index.

To reduce the risk of Type I errors, the results were corrected for multiple comparisons using the False Discovery Rate (FDR) approach set at an $\alpha$ level of 0.05 . For each covariate, which remained significant after correction for multiple comparisons, the $F$ value, the uncorrected $p$ value, and Cohen's $d$ (Borenstein, 2009), including the 95\% CIs ( $d(\mathrm{CI}))$, are reported (Table 4 ). All analyses were performed using R version 3.0.0 (http://www.r-project.org). $\mathrm{R}$ is an open source toolbox for statistical computing running under Unix (Ubuntu Linux used here) and providing a variety of advanced statistical tests.

Shape analysis. The same comparisons performed to investigate differences of volume were performed for each of the following structures to investigate differences of shape: thalamus, globus pallidus, and striatum at vertex level to investigate differences. Age, gender, MRI scanner, $\mathrm{nBV}$, and the interaction terms were included in the model in a stepwise fashion if significant. Results were corrected for multiple comparisons using FDR at an $\alpha$ level of 0.05 . These analyses were performed using the RMINC package ( $\mathrm{R}$ for Medical Imaging NetCDF), an image analysis software library developed for R. 
Table 4. Statistical results of ANCOVA model between migraineurs and controls ${ }^{a}$

\begin{tabular}{llrll}
\hline \multirow{2}{*}{ Brain structure } & $\begin{array}{l}\text { Significant } \\
\text { covariates }\end{array}$ & \multicolumn{1}{l}{ F(dof) } & Uncorrected $p$ & Cohen's d(Cl) \\
\hline Anterior thalamic & Groups & $7.38(1,237)$ & 0.007 & $0.3(0.1-0.6)$ \\
nucleus & MRI scanner & $10.52(4,237)$ & 0.0001 & \\
& nBV & $43.73(1,237)$ & 0.0001 & \\
Central thalamic & Groups & $6.79(1,233)$ & 0.009 & $0.3(0.1-0.5)$ \\
nuclear complex & MRI scanner & $4.72(4,233)$ & 0.0001 & \\
& nBV & $102.38(1,233)$ & 0.0001 & \\
Lateral dorsal & Gender & $7.04(1,233)$ & 0.01 & \multirow{2}{*}{$0.3(0.1-0.6)$} \\
thalamic nucleus & Groups & $6.79(1,238)$ & 0.009 & \\
& MRI scanner & $8.59(4,238)$ & 0.001 & $0.3(0.1-0.5)$ \\
Striatum & nBV & $11.56(1,238)$ & 0.0001 & \\
& Groups & $6.9(1,238)$ & 0.009 & \\
& MRI scanner & $13.56(4,238)$ & 0.0001 & \\
& nBV & $258.73(1,238)$ & 0.0001 & \\
\hline
\end{tabular}

${ }^{a}$ For each statistical model, only covariates, which were significant after correction for multiple comparisons (FDRcorrected threshold of $p<0.05$ ), are shown.
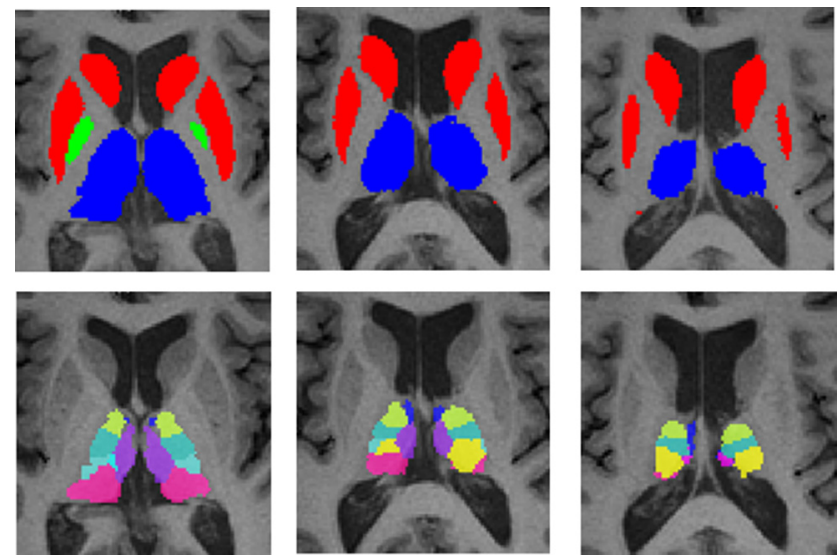

Figure 1. Exemplary subcortical segmentation of one study patient. First row, Thalamus (blue), striatum (red), and globus pallidus (green). Second row, Segmented thalamic subnuclei.

\section{Results}

The power analysis showed that, with the sample size of the overall study population, it is possible to detect differences between groups with a small/medium effect size.

After visual accuracy assessment, we concluded that all nuclei were accurately segmented (Fig. 1).

In patients with migraine, we found a statistically significant volume reduction (corrected for multiple comparisons) in the following thalamic subnuclei (Fig. 2): anterior thalamic nucleus (ATN; $247 \pm 46 \mathrm{~mm}^{3}$ vs $269 \pm 44 \mathrm{~mm}^{3}$ ), central nuclear complex $\left(\mathrm{CN} ; 459 \pm 47 \mathrm{~mm}^{3}\right.$ vs $480 \pm 53 \mathrm{~mm}^{3}$ ), and lateral dorsal nucleus $\left(\mathrm{LDN} ; 52 \pm 18 \mathrm{~mm}^{3}\right.$ vs $60 \pm 16 \mathrm{~mm}^{3}$ ). MRI scanner and $\mathrm{nBV}$ were identified as significant covariates for all these nuclei (ATN, $\mathrm{CN}$, and LDN) as well as gender only for the CN. Moreover, the volume of the striatum was significantly reduced in patients with migraine compared with healthy subjects $\left(16,886 \pm 1857 \mathrm{~mm}^{3}\right.$ vs $17,817 \pm 1942 \mathrm{~mm}^{3}$ ) with MRI scanner and nBV as significant covariates (Table 4). No significant differences between groups were observed in the globus pallidus. For each tested model, the interaction terms were not statistically significant. All other planned subgroup comparisons (healthy subjects vs MwA, healthy subjects vs MwoA, MwA vs MwoA, and contralateral vs ipsilateral thalamus in patients with predominantly lateralized migraine) did not show significant differences after correction for multiple comparisons. Disease duration and days of headache per month were not significantly related to any volume. All AN-
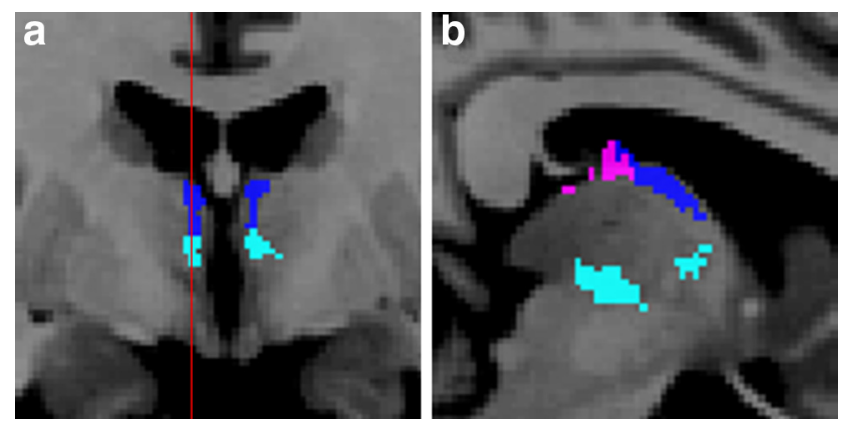

Figure 2. The location and size of the thalamic nuclei with smaller volumes in patients with migraine compared with healthy subjects (according to Hirai and Jones nomenclature). In these nuclei, significant between-group differences (migraine vs controls) were observed at a significance level of $p<0.05$ (FDR corrected). The atlas labels are shown and overlaid on highresolution T1-weighted MRI images (Colin27 MRI template). Blue represents anterior nucleus. Pink represents lateral dorsal nucleus. Cyan represents central nuclear complex. $\boldsymbol{a}$, Coronal view. b, Sagittal view.

COVA and MLR models met the assumptions and were thus accurate for the sample and generalizable to the population level.

The shape analysis showed neither significant displacement differences between groups nor any relation to clinical features.

\section{Discussion}

In the present study, we investigated the morphology of the thalamus and basal ganglia in a large multicenter cohort of patients with migraine using high-resolution MRI data acquired on stateof-the-art 3 tesla scanners. The comparisons with healthy subjects revealed that patients had smaller volumes of the central nuclear complex, the anterior nucleus, and the dorsolateral nucleus. Moreover, patients had smaller striatal volumes. However, no relationship to clinical parameters was found.

The affected thalamic nuclei are all part of a limbic corticalsubcortical network involved in the processing of affective and cognitive components of pain (Rainville, 2002; Vogt, 2005). The limbic system has been previously suggested as an important component of migraine pathophysiology (Burstein and Jakubowski, 2005; O'Carroll, 2007), and several small studies have shown abnormalities of limbic regions in patients with migraine. Specifically, interictal hypometabolism has been reported in patients with migraine in the insula, cingulate cortex (CC), and prefrontal cortex using PET (Kim et al., 2010) and a reduction of gray matter density using voxel-based morphometry in the insula, CC, and frontal gyri (Rocca et al., 2006; Schmidt-Wilcke et al., 2008), supporting the importance of the limbic system in migraine pathophysiology. However, it has to be kept in mind that the spatial resolution of MRI at 3 tesla does not currently allow to dissect the reductions of volume in terms of underlying microstructural changes. Volume changes as evidenced by MRI may be influenced by many different pathophysiological processes, including change of synaptic and neuronal density, abnormal dendritic arborization, abnormalities of white matter within the thalamus, abnormal water content, and many other processes (Vercellino et al., 2009; Sinjab et al., 2013). In the future, it may be useful to combine neuroimaging with electrophysiological recordings to better understand how structural and functional abnormalities are related in migraine (de Tommaso et al., 2014). Electrophysiological methods may also be better suited to determine alterations in the sensory trigeminal-thalamic system at present (de Tommaso et al., 2014). 


\section{Specific role and neuroanatomical connections of affected thalamic nuclei}

The central nuclear complex belongs to the intralaminar nuclei and includes the central medial nucleus (CM) and the parafascicular nucleus (Pf). The CM/Pf complex has reciprocal connections with the prefrontal cortex and cingulate cortex (Sadikot and Rymar, 2009) and receives dense input from the basal ganglia (Van der Werf et al., 2002; Sadikot and Rymar, 2009; Vertes et al., 2012). It has been reported that the intralaminar nuclei, including the CM/Pf complex, are relevant for synchronizing/desynchronizing the activity between different brain networks according to behavioral demands (Saalmann, 2014). Interestingly, previous studies have indicated abnormal cortical synchronization patterns in patients with migraine compared with healthy subjects (de Tommaso et al., 2007).

Moreover, the CM/Pf nuclear complex projects densely to the striatum and cortex (Goadsby et al., 1993; Benarroch, 2008). More specifically, the CM projects to sensorimotor regions of the striatum, whereas the Pf projects to cognitive and limbic regions of the striatum (Van der Werf et al., 2002; Saalmann, 2014). Together with the observation of striatal volume reductions in our study, this suggests an involvement of thalamostriatal loops in migraine pathogenesis. Indeed, the striatum, due to its widespread reciprocal cortical connections, is involved in a variety of brain functions. Previously, Maleki et al. (2011) reported an altered response to experimental pain stimulation in the striatum and an increased volume of the caudate nucleus in patients with higher migraine frequency.

The main input of the ATN originates from the subiculum, the anterior cingulate cortex (ACC), the posterior cingulate cortex, the retrosplenial cortex, and the inferior parietal lobule. It also receives input from the amygdala and hypothalamus and projects mainly to the hippocampal formation via the anterior and posterior CC and the retrosplenial cortex (Child and Benarroch, 2013). This network suggests a role of ATN in brain functions, such as emotion, cognitive control, and pain processing (Vogt, 2005; Shackman et al., 2011). The CC is part of the limbic system and one of the key structures of the pain matrix (Fuchs et al., 2014). Specifically, the ACC and anterior midcingulate cortex (aMCC) have connections to the orbitofrontal cortex, and amygdala, and are therefore thought to be involved in the processing of emotions as well as cognition and thus in the processing of the affective component of pain (Vogt, 2014). Several studies have shown decreases of gray matter density in the CC (Rocca et al., 2006; Kim et al., 2008; Schmidt-Wilcke et al., 2008) as well as a differential response of ACC and aMCC during pain stimulation when comparing healthy subjects (Aderjan et al., 2010; Russo et al., 2012) with patients with migraine. Moreover, the involvement of the anterior portion of the thalamus is consistent with previous functional and morphological observations. Indeed, Afridi et al. (2005) reported an increased activity of the anterior thalamus during acute migraine attacks as studied by PET. Granziera et al. (2014) observed microstructural alterations with shorter $\mathrm{T} 1$ and $\mathrm{T} 2$ * relaxation times and higher magnetization transfer ratios in the thalamus of patients with MwA. Although they did not specifically quantify the structural abnormalities in specific thalamic nuclei, the alterations seem to affect the ATN and the LDN. The LDN is located posteriorly and adjacent to the ATN. These two nuclei are structurally similar and share similar connectivity (Aggleton et al., 2014). Noseda et al. (2011) observed in animal models that trigeminal neurons located in the posterior nucleus, LDN, and lateral-posterior nucleus project to the trigeminal and nontrigeminal somatosensory cortex (S1 and S2), motor cortex (M1), and visual cortex (V1 and $\mathrm{V} 2$ ). The authors interpreted the broad connections between trigeminal neurons localized in these thalamic nuclei and the cortex as a possible explanation for a variety of neurological symptoms associated with migraine (Noseda et al., 2011).

\section{Lack of correlation with clinical characteristics and study limitations}

We did not observe a relation between the volumes of thalamic nuclei and clinical characteristics, such as headache frequency or the duration of the disorder, in our cohort of patients. The volume reductions of specific thalamic nuclei may instead relate to the genetic background of patients with migraine. An alternative explanation may be that age-related plasticity masks plasticity associated with the disorder. It has been shown that age can lead to both increases as well as decreases of dendritic size or number of synapses, potentially leveling out disease-related plasticity when a compound outcome, such as thalamic volume, is applied (Kolb et al., 2003; Kolb and Gibb, 2010, 2014).

These considerations point out the complex relationship between disease evolution and brain morphological changes, which may not be sufficiently described by a linear association over the lifespan and course of a disorder. This complex relation could also explain the somewhat inconsistent results regarding volume of brain structures of patients with migraine reported in previous studies (Maleki et al., 2011). In this regard, the cross-sectional design of our study is a limitation. Longitudinal studies, including an exhaustive assessment of brain functions, may be needed to clarify the relation between morphological changes and clinical features and the role of limbic structures in the pathophysiology of the disorder. Indeed, Liu et al. (2013) investigated brain morphological changes longitudinally in a group of patients with newly diagnosed MwoA with two structural MRI sessions 1 year apart. They reported cortical gray matter changes in brain regions involved in the processing of pain. These results support the view of cortical gray matter changes as a consequence of the ongoing disorder, at least at early stages of the disorder.

Another potential limitation of our study relates to the T1weighted images as the only input for the segmentation of the thalamic nuclei. It has been suggested that a multimodal imaging strategy (T1-and T2-weighted images, and diffusion tensor images) could improve the segmentation accuracy (Traynor et al., 2011). The large sample size of our study and the use of a wellvalidated multiatlas segmentation technique outweigh these potential disadvantages in terms of segmentation accuracy.

In the ANCOVA model, scanner type turned out to be a significant covariate. This is not surprising considering the well-known variability in coil and gradient properties between scanners. However, the interaction terms of the ANCOVA models were not statistically significant; and hence, the impact of the scanner type is the same in patients and controls and should therefore not influence group differences between patients and controls.

We pooled data of patients with migraine with and without aura. The subgroup analyses of only patients with aura and only patients without aura versus healthy subjects, did not show significant results after correction for multiple comparisons. This might be caused by the smaller sample sizes in the subgroup analyses. Together, we cannot exclude that there are specific abnormalities in either migraine with or without aura. However, there is so far no strong indication that the underlying migraine biology is different in patients with versus without aura.

The study indicates morphological abnormalities in several thalamic nuclei in patients with migraine. The neuroanatomical 
connections of the affected nuclei suggest that they contribute to the limbic system. The findings lend support to the view that higher-order integration systems are abnormal in terms of structure (Maizels et al., 2012), which in turn may alter function in migraine.

\section{References}

Aderjan D, Stankewitz A, May A (2010) Neuronal mechanisms during repetitive trigemino-nociceptive stimulation in migraine patients. Pain 151: 97-103. CrossRef Medline

Afridi SK, Giffin NJ, Kaube H, Friston KJ, Ward NS, Frackowiak RS, Goadsby PJ (2005) A positron emission tomographic study in spontaneous migraine. Arch Neurol 62:1270-1275. CrossRef Medline

Aggleton JP, Saunders RC, Wright NF, Vann SD (2014) The origin of projections from the posterior cingulate and retrosplenial cortices to the anterior, medial dorsal and laterodorsal thalamic nuclei of macaque monkeys. Eur J Neurosci 39:107-123. CrossRef Medline

Avants BB, Epstein CL, Grossman M, Gee JC (2008) Symmetric diffeomorphic image registration with cross-correlation: evaluating automated labeling of elderly and neurodegenerative brain. Med Image Anal 12: 26-41. CrossRef Medline

Benarroch EE (2008) The midline and intralaminar thalamic nuclei: anatomic and functional specificity and implications in neurologic disease. Neurology 71:944-949. CrossRef Medline

Borenstein M (2009) Effect sizes for continuous data. In: The handbook of research synthesis and meta-analysis (Cooper $\mathrm{H}$, Hedges LV, Valentine JC, eds), pp 279-293. New York: Russel Sage Foundation.

Brown MB, Forsythe AB (1974) Robust tests for equality of variances. J Am Stat Assoc 69:364-367. CrossRef

Burstein R, Jakubowski M (2005) Unitary hypothesis for multiple triggers of the pain and strain of migraine. J Comp Neurol 493:9-14. CrossRef Medline

Chakravarty MM, Bertrand G, Hodge CP, Sadikot AF, Collins DL (2006) The creation of a brain atlas for image guided neurosurgery using serial histological data. Neuroimage 30:359-376. CrossRef Medline

Chakravarty MM, Sadikot AF, Germann J, Bertrand G, Collins DL (2008) Towards a validation of atlas warping techniques. Med Image Anal 12: 713-726. CrossRef Medline

Chakravarty MM, Rosa-Neto P, Broadbent S, Evans AC, Collins DL (2009a) Robust S1, S2, and thalamic activations in individual subjects with vibrotactile stimulation at 1.5 and 3.0 T. Hum Brain Mapp 30:1328-1337. CrossRef Medline

Chakravarty MM, Sadikot AF, Germann J, Hellier P, Bertrand G, Collins DL (2009b) Comparison of piece-wise linear, linear, and nonlinear atlas-topatient warping techniques: analysis of the labeling of subcortical nuclei for functional neurosurgical applications. Hum Brain Mapp 30:35743595. CrossRef Medline

Chakravarty MM, Steadman P, van Eede MC, Calcott RD, Gu V, Shaw P, Raznahan A, Collins DL, Lerch JP (2013) Performing label-fusionbased segmentation using multiple automatically generated templates. Hum Brain Mapp 34:2635-2654. CrossRef Medline

Child ND, Benarroch EE (2013) Anterior nucleus of the thalamus: functional organization and clinical implications. Neurology 81:1869-1876. CrossRef Medline

Collins DL, Pruessner JC (2010) Towards accurate, automatic segmentation of the hippocampus and amygdala from MRI by augmenting ANIMAL with a template library and label fusion. Neuroimage 52:1355-1366. CrossRef Medline

Coppola G, Tinelli E, Lepre C, Iacovelli E, Di Lorenzo C, Di Lorenzo G, Serrao M, Pauri F, Fiermonte G, Bianco F, Pierelli F (2014) Dynamic changes in thalamic microstructure of migraine without aura patients: a diffusion tensor magnetic resonance imaging study. Eur J Neurol 21:287-292. CrossRef Medline

DaSilva AF, Granziera C, Tuch DS, Snyder J, Vincent M, Hadjikhani N (2007) Interictal alterations of the trigeminal somatosensory pathway and periaqueductal gray matter in migraine. Neuroreport 18:301-305. CrossRef Medline

de Tommaso M, Marinazzo D, Nitti L, Pellicoro M, Guido M, Serpino C, Stramaglia S (2007) Effects of levetiracetam vs topiramate and placebo on visually evoked phase synchronization changes of alpha rhythm in migraine. Clin Neurophysiol 118:2297-2304. CrossRef Medline

de Tommaso M, Ambrosini A, Brighina F, Coppola G, Perrotta A, Pierelli F,
Sandrini G, Valeriani M, Marinazzo D, Stramaglia S, Schoenen J (2014) Altered processing of sensory stimuli in patients with migraine. Nat Rev Neurol 10:144-155. CrossRef Medline

Faul F, Erdfelder E, Lang AG, Buchner A (2007) G* Power 3: a flexible statistical power analysis program for the social, behavioral, and biomedical sciences. Behav Res Methods 39:175-191. CrossRef Medline

Frey S, Pandya DN, Chakravarty MM, Bailey L, Petrides M, Collins DL (2011) An MRI based average macaque monkey stereotaxic atlas and space (MNI monkey space). Neuroimage 55:1435-1442. CrossRef Medline

Fuchs PN, Peng YB, Boyette-Davis JA, Uhelski ML (2014) The anterior cingulate cortex and pain processing. Front Integr Neurosci 8:1-10. CrossRef Medline

Goadsby PJ, Seylaz J, Mraovitch S (1993) Noncholinergic, nonadrenergic cortical vasodilatation elicited by thalamic centromedian-parafascicular complex. Am J Physiol 264:R1150-R1156. Medline

Granziera C, Daducci A, Romascano D, Roche A, Helms G, Krueger G, Hadjikhani N (2014) Structural abnormalities in the thalamus of migraineurs with aura: a multiparametric study at 3 T. Hum Brain Mapp 35:1-8. CrossRef Medline

Headache Classification Committee of the International Headache Society (2013) The International Classification of Headache Disorders, 3rd edition (beta version). Cephalalgia 33:629-808. CrossRef Medline

Hirai T, Jones EG (1989) A new parcellation of the human thalamus on the basis of histochemical staining. Brain Res Brain Res Rev 14:1-34. CrossRef Medline

Ivanov I, Bansal R, Hao X, Zhu H, Kellendonk C, Miller L, Sanchez-Pena J, Miller AM, Chakravarty MM, Klahr K, Durkin K, Greenhill LL, Peterson BS (2010) Morphological abnormalities of the thalamus in youths with attention deficit hyperactivity disorder. Am J Psychiatry 167:397-408. CrossRef Medline

Kim JH, Suh SI, Seol HY, Oh K, Seo WK, Yu SW, Park KW, Koh SB (2008) Regional grey matter changes in patients with migraine: a voxel-based morphometry study. Cephalalgia 28:598-604. CrossRef Medline

Kim JH, Kim S, Suh SI, Koh SB, Park KW, Oh K (2010) Interictal metabolic changes in episodic migraine: a voxel-based FDG-PET study. Cephalalgia 30:53-61. CrossRef Medline

Kolb B, Gibb R (2010) Tactile stimulation after frontal or parietal cortical injury in infant rats facilitates functional recovery and produces synaptic changes in adjacent cortex. Behav Brain Res 214:115-120. CrossRef Medline

Kolb B, Gibb R (2014) Searching for the principles of brain plasticity and behavior. Cortex 58:251-260. CrossRef Medline

Kolb B, Gibb R, Gorny G (2003) Experience-dependent changes in dendritic arbor and spine density in neocortex vary qualitatively with age and sex. Neurobiol Learn Mem 79:1-10. CrossRef Medline

Lerch JP, Carroll JB, Spring S, Bertram LN, Schwab C, Hayden MR, Henkelman RM (2008) Automated deformation analysis in the YAC128 Huntington disease mouse model. Neuroimage 39:32-39. CrossRef Medline

Liu J, Lan L, Li G, Yan X, Nan J, Xiong S, Yin Q, von Deneen KM, Gong Q, Liang F, Qin W, Tian J (2013) Migraine-related gray matter and white matter changes at a 1-year follow-up evaluation. J Pain 14:1703-1708. CrossRef Medline

Magon S, Chakravarty MM, Amann M, Weier K, Naegelin Y, Andelova M, Radue EW, Stippich C, Lerch JP, Kappos L, Sprenger T (2014) Labelfusion-segmentation and deformation-based shape analysis of deep gray matter in multiple sclerosis: the impact of thalamic subnuclei on disability. Hum Brain Mapp 35:4193-4203. CrossRef Medline

Maizels M, Aurora S, Heinricher M (2012) Beyond neurovascular: migraine as a dysfunctional neurolimbic pain network. Headache 52:1553-1565. CrossRef Medline

Maleki N, Becerra L, Nutile L, Pendse G, Brawn J, Bigal M, Burstein R, Borsook D (2011) Migraine attacks the basal ganglia. Mol Pain 7:71-82. CrossRef Medline

Maniyar FH, Sprenger T, Monteith T, Schankin C, Goadsby PJ (2014) Brain activations in the premonitory phase of nitroglycerin-triggered migraine attacks. Brain 137:232-241. CrossRef Medline

Miller AM, Bansal R, Hao X, Sanchez-Pena JP, Sobel LJ, Liu J, Xu D, Zhu H, Chakravarty MM, Durkin K, Ivanov I, Plessen KJ, Kellendonk CB, Peterson BS (2010) Enlargement of thalamic nuclei in Tourette syndrome. Arch Gen Psychiatry 67:955-964. CrossRef Medline

Murray CJ, Vos T, Lozano R, Naghavi M, Flaxman AD, Michaud C, Ezzati M, Shibuya K, Salomon JA, Abdalla S, Aboyans V, Abraham J, Ackerman I, Aggarwal R, Ahn SY, Ali MK, Alvarado M, Anderson HR, Anderson LM, Andrews KG, et 
al. (2012) Disability-adjusted life years (DALYs) for 291 diseases and injuries in 21 regions, 1990-2010: a systematic analysis for the Global Burden of Disease Study 2010. Lancet 380:2197-2223. CrossRef Medline

Noseda R, Jakubowski M, Kainz V, Borsook D, Burstein R (2011) Cortical projections of functionally identified thalamic trigeminovascular neurons: implications for migraine headache and its associated symptoms. J Neurosci 31:14204-14217. CrossRef Medline

O'Carroll CP (2007) Migraine and the limbic system: closing the circle. Psychopharmacol Bull 40:12-23. Medline

Pipitone J, Park MT, Winterburn J, Lett TA, Lerch JP, Pruessner JC, Lepage M, Voineskos AN, Chakravarty MM (2014) Multi-atlas segmentation of the whole hippocampus and subfields using multiple automatically generated templates. Neuroimage 101:494-512. CrossRef Medline

Rainville P (2002) Brain mechanisms of pain affect and pain modulation. Curr Opin Neurobiol 12:195-204. CrossRef Medline

Rocca MA, Ceccarelli A, Falini A, Colombo B, Tortorella P, Bernasconi L, Comi G, Scotti G, Filippi M (2006) Brain gray matter changes in migraine patients with T2-visible lesions: a 3-T MRI study. Stroke 37:17651770. CrossRef Medline

Royston P (1982) An extension of Shapiro and Wilk's W test for normality to large samples. Appl Stat 31:115-124. CrossRef

Russo A, Tessitore A, Esposito F, Marcuccio L, Giordano A, Conforti R, Truini A, Paccone A, d'Onofrio F, Tedeschi G (2012) Pain processing in patients with migraine: an event-related fMRI study during trigeminal nociceptive stimulation. J Neurol 259:1903-1912. CrossRef Medline

Saalmann YB (2014) Intralaminar and medial thalamic influence on cortical synchrony, information transmission and cognition. Front Syst Neurosci 8:83. CrossRef Medline

Sadikot AF, Rymar VV (2009) The primate centromedian-parafascicular complex: anatomical organization with a note on neuromodulation. Brain Res Bull 78:122-130. CrossRef Medline

Schmidt-Wilcke T, Gänssbauer S, Neuner T, Bogdahn U, May A (2008) Subtle grey matter changes between migraine patients and healthy controls. Cephalalgia 28:1-4. CrossRef Medline
Shackman AJ, Salomons TV, Slagter HA, Fox AS, Winter JJ, Davidson RJ (2011) The integration of negative affect, pain and cognitive control in the cingulate cortex. Nat Rev Neurosci 12:154-167. CrossRef Medline

Sinjab B, Martinian L, Sisodiya SM, Thom M (2013) Regional thalamic neuropathology in patients with hippocampal sclerosis and epilepsy: a postmortem study. Epilepsia 54:2125-2133. CrossRef Medline

Smith SM, Jenkinson M, Woolrich MW, Beckmann CF, Behrens TE, Johansen-Berg H, Bannister PR, De Luca M, Drobnjak I, Flitney DE, Niazy RK, Saunders J, Vickers J, Zhang Y, De Stefano N, Brady JM, Matthews PM (2004) Advances in functional and structural MR image analysis and implementation as FSL. Neuroimage 23 [Suppl 1]:S208-S219.

Traynor CR, Barker GJ, Crum WR, Williams SC, Richardson MP (2011) Segmentation of the thalamus in MRI based on T1 and T2. Neuroimage 56:939-950. CrossRef Medline

Valfrè W, Rainero I, Bergui M, Pinessi L (2008) Voxel-based morphometry reveals gray matter abnormalities in migraine. Headache 48:109-117. CrossRef Medline

Van der Werf YD, Witter MP, Groenewegen HJ (2002) The intralaminar and midline nuclei of the thalamus: anatomical and functional evidence for participation in processes of arousal and awareness. Brain Res Brain Res Rev 39:107-140. CrossRef Medline

Vercellino M, Masera S, Lorenzatti M, Condello C, Merola A, Mattioda A, Tribolo A, Capello E, Mancardi GL, Mutani R, Giordana MT, Cavalla P (2009) Demyelination, inflammation, and neurodegeneration in multiple sclerosis deep gray matter. J Neuropathol Exp Neurol 68:489-502. CrossRef Medline

Vertes RP, Hoover WB, Rodriguez JJ (2012) Projections of the central medial nucleus of the thalamus in the rat: node in cortical, striatal and limbic forebrain circuitry. Neuroscience 219:120-136. CrossRef Medline

Vogt BA (2005) Pain and emotion interactions in subregions of the cingulate gyrus. Nat Rev Neurosci 6:533-544. CrossRef Medline

Vogt BA (2014) Submodalities of emotion in the context of cingulate subregions. Cortex 59:197-202. CrossRef Medline 